\title{
Da TI Reativa para uma TI Estratégica
}

\author{
From Reactive IT to Strategic IT
}

\author{
Claudio Roberto da Costa Junior ${ }^{1}$ \\ Thais Gonzaga dos Santos ${ }^{2}$ \\ Sidnei Vieira Marinho ${ }^{3}$ \\ Anete Alberton ${ }^{4}$
}

\begin{abstract}
Resumo
Este caso de ensino apresenta a história de Carlos, gerente na área de Tecnologia da Informação (TI), que vem sendo bastante pressionado, nos últimos tempos, pelos usuários da empresa e por seu diretor, pois não consegue atender a todos como gostaria e quem reclama mais é atendido primeiro. Sua área tem muitos projetos e atividades para fazer, mas ele não tem visibilidade do volume e da situação dos projetos. Todos têm a mesma prioridade, independentemente do tamanho e importância. Seu cargo está em risco na empresa, todos questionam os altos valores investidos na área de TI, pois não conseguem perceber o retorno dos investimentos para o resultado da empresa. A situação de Carlos serve de exemplo para muitos gestores de TI que acabam atuando focados somente na gestão operacional da área, e têm muita dificuldade de se posicionar de forma estratégica. É uma situação que envolve áreas de TI de empresas de vários segmentos de mercado, principalmente em empresas de pequeno e médio porte, em que a equipe é mais enxuta. Neste formato, está difícil trabalhar. Todos da equipe de TI estão desanimados e esse é o momento de propor algo diferente para a empresa, demonstrando que a área de TI pode e deve ser um parceiro estratégico da empresa.
\end{abstract}

Palavras-chave: Processos. Gestão de Projetos. Estratégia. Tecnologia da Informação.

\begin{abstract}
This case study teaching presents Carlos's story, Information Technology's Manager area (IT), who has been under pressure in recent times by the users of the company and his Director, because he can't satisfy everyone as he'd like, and the one who complains most is attended first. Your area has many projects and activities to do, but he has no visibility of the volume and status of projects, they all have the same priority regardless of size and importance. His position is on risk in the company, they all questions the high values invested in the IT area, because they can't perceive the return of these investments to the company's result. Carlos's situation serves as an example for many IT managers who end up only focused on the operational management of the area, and who have much difficulty in positioning themselves strategically. It's a situation that concerns IT areas of companies from many market segments, especially in small and medium business where the team is lower. This form is difficult to work, all of the IT staff are discouraged and this is the time to propose something different for the company, showing that IT should be a strategic partner of the company.
\end{abstract}

Keywords: Processes. Project Management. Strategy. Information Technology.

\section{Operação tapa-buracos}

Carlos foi contratado para gerenciar uma equipe na área de Tecnologia da Informação na empresa MANLAN, uma empresa de médio porte que atua no segmento metal mecânico. O gerente de TI anterior

\footnotetext{
Mestrando do Programa de Mestrado Profissional em Gestão Empresarial, Internacionalização e Logística (PMPGIL) da Universidade do Vale do Itajaí (UNIVALI). Brasil. Afiliação: UNIVALI. Lattes: http://lattes.cnpq.br/1803790444616986 Email: claudio.costa@euax.com.br

2 Mestranda do Programa de Mestrado Profissional em Gestão Empresarial, Internacionalização e Logística (PMPGIL) da Universidade do Vale do Itajaí (UNIVALI). Brasil. Afiliação: UNIVALI. Lattes: http://lattes.cnpq.br/2248781937465491 Email: thaisgonzaga.tg@gmail.com

3 Doutorado em Engenharia de Produção (2006) pela Universidade Federal de Santa Catarina (UFSC). Brasil. Afiliação: Universidade do Vale do Itajaí (UNIVALI). Lattes: http://lattes.cnpq.br/9021723203921809 Email: sidnei@univali.br

4 Doutorado e Mestrado em Engenharia de Produção (2003 e 1996). Brasil. Afiliação: Universidade do Vale do Itajaí (UNIVALI). Lattes: http:// lattes.cnpq.br/5451127583047484 Email: anete@univali.br
} 
a Carlos foi demitido da empresa por não conseguir atender às solicitações das áreas, sempre estava devendo atividades e os projetos costumavam atrasar demais.

A área de tecnologia da informação que Carlos recebeu para gerenciar tem uma equipe com 11 profissionais, dos quais quatro atuam com a parte de infraestrutura de TI e seis ficam na equipe de sistemas, e o Carlos. Atendem, aproximadamente, 200 usuários, divididos entre as áreas de negócio da empresa, e possuem um sistema de gestão empresarial (ERP) de mercado. A equipe desenvolve alguns sistemas específicos internamente, como controle de despesas de viagem; e também todas as customizações menores solicitadas pelos usuários.

Assim que chegou, não teve muito tempo para se ambientar, pois o escritório já estava com um backlog muito grande de demandas e projetos necessitando de soluções da TI, e Carlos não hesitou, iniciou com fôlego total. Desde o primeiro dia, ficava até tarde no escritório para dar conta das atividades, e assim foi por mais de seis meses a fio. Até que Carlos percebeu que isso não iria parar, demandas e mais demandas de novos projetos acumulando, sem ordem de prioridade e sem um estudo prévio para entender o contexto e definir a urgência. Após algumas frustrações, começou a perceber que a estratégia da empresa para a área de TI sempre foi ter uma equipe enxuta para não aumentar o custo, apesar dos vários projetos que as áreas demandam a todo instante.

Para complicar ainda mais sua vida, a família, que ele tanto preza, começou a pressioná-lo para dar mais atenção aos eventos familiares, pois, nos últimos aniversários de familiares, não pôde ir por estar trabalhando, mesmo sendo em finais de semana. Carlos sempre se dedicou muito para dar conforto para sua esposa e filhos, mas, nos últimos tempos, estava ausente e foi alertado que precisava encontrar um equilíbrio entre a vida pessoal e profissional.

\section{Chamem os bombeiros}

Conversando com alguns colegas de trabalho, todos reconhecem que a área de TI sempre teve um papel muito operacional. É vista por alguns diretores como um mal necessário para a empresa; para outros, como um mero centro de custos, pois os valores para manter os sistemas e a infraestrutura são considerados bem altos. Se pudessem optar, iriam investir o dinheiro para comprar mais equipamentos para o chão de fábrica ou trocar a frota de veículos, por exemplo.

Carlos vem sendo bastante pressionado nos últimos tempos por todas as áreas, não consegue atender a todos como gostaria e, atualmente, quem reclama mais é atendido primeiro. Como não sabia exatamente qual a situação de cada projeto pelo qual estava sendo cobrado, resolveu fazer uma reunião com a equipe para ter uma visão sobre a lista de pendências, e pediu para que cada responsável de projetos da equipe de TI identificasse somente os projetos que tinha sob sua responsabilidade, informando ainda com base na sua percepção a situação de cada um. As atividades de rotina e as operações do dia a dia não deveriam ser consideradas nesse levantamento, somente os projetos. Para nortear essa atividade, definiram que projetos que tivessem esforço de até 160 horas de trabalho seriam considerados de baixo porte; de 161 a 320 horas de trabalho, seriam considerados de médio porte; e aqueles acima de 320 horas de trabalho seriam classificados como de grande porte.

Nesse levantamento rápido que fizeram, conforme anexo 1, identificaram 21 projetos, e já foi possível perceber que tinham $11 \mathrm{em}$ atraso, sendo sete com estimativa de baixo esforço e que sem o escopo bem definido, e outros quatro um pouco mais complexos, com escopo bem definido e orçamento alto, que pareciam ser muito importantes e urgentes, pois envolvem equipes internas e externas, e os prazos já estavam definidos e acordados com os clientes. Além dos projetos em atraso, existiam mais seis de grande porte em andamento e com chances de atrasar, e mais quatro de grande porte que estavam pendentes de avaliação por parte da equipe, que eram estratégicos para a empresa e a pressão estava grande para começarem.

Carlos acredita que são muitos projetos e atividades para fazer ao mesmo tempo, mas reconhece que não tem uma gestão adequada, não tem a visibilidade da posição de todas as demandas de forma detalhada (prazo, custo, escopo e qualidade) e também não sabe se a produtividade da equipe está boa 
ou não. Na sua percepção, com a equipe atual, não dá para atender tudo que vem de solicitação. Ele pensa que só aumentando o número de colaboradores para resolver, mas não consegue demonstrar essa necessidade por meio da produtividade da equipe, de forma clara, para o diretor Celso, e sempre recebe um não quando solicita mais profissionais.

Celso já o chamou quatro vezes para alinhamento das estratégias e, na última reunião, disse que não aguenta mais segurar os outros diretores e usuários reclamando da área de TI. Se não der um jeito em, no máximo, quatro meses, terá que buscar outra alternativa. Ele sabe que Carlos e a equipe de TI são muito comprometidos e dedicados, mas isso não é o suficiente para o que a empresa precisa.

Está claro para Carlos que não dá mais para continuar assim, fazendo papel de "bombeiro", apagando incêndio toda hora e atendendo a todos pelo grito. Mas ele não sabe por onde começar a resolver essas questões de processos e prioridades, nem que decisão deve tomar. Ele acredita que a saída seja montar um projeto para transformar a área de TI num parceiro estratégico da organização. Mas como? Sua equipe está toda desatualizada em relação às boas práticas de gestão de projetos e TI, pois nem cursos consegue aprovar com a diretoria. Cada um da equipe faz o seu serviço com base em conhecimento e experiência próprios, não existem processos estabelecidos para desenvolver os projetos e as demais atividades, e reconhece que acaba sendo um grande risco para a empresa, pois, se alguém sair, leva todo conhecimento junto, além de poder trazer prejuízo para a operação atual e demoraria algum tempo para treinar outra pessoa para atuar no mesmo lugar. O ponto positivo é que a equipe de TI é muito comprometida com a empresa, todos pegam juntos e são colaborativos, mas também estão desgastados com as críticas, de forma que a moral da equipe está baixa.

Para piorar a situação, durante um intervalo para um cafezinho, Carlos, conversando com seu subordinado Mário, que já trabalha há cinco anos na equipe de sistemas, soube que ele está pensando em se desligar da MANLAN e tentar uma vaga em alguma outra empresa, que tenha mais tecnologias de ponta e processos mais bem definidos, pois está descontente com a situação atual. Isto deixou Carlos mais preocupado ainda, pois Mário conhece muito bem o sistema de logística e conseguiu fazer uma boa amizade com os usuários dessa área; fazendo com que, praticamente, não se tenha reclamações desse setor. Outra agravante é que Mário não documenta nada, já que sabe tudo de cabeça. Se ele sair da empresa, será muito complicado e demorado para treinar um substituto.

Além disso, uma das coisas que perturba Carlos é ter que atender primeiro quem reclama mais. Estão com seis projetos em andamento, sendo três projetos de logística: uma implantação do Sistema de Gerenciamento de Armazéns (WMS), uma otimização do processo de entregas, e um projeto de redução de custos de embalagens; o desenvolvimento de uma melhoria no sistema de força de vendas para a área do comercial; a implantação do sistema para atender a legislação do e-social para o RH; e ainda está sendo cobrado de um projeto solicitado pela diretoria sobre uma nova campanha de marketing, que precisa ser lançada em 120 dias; fora os outros 11 projetos que já estão atrasados.

Como não tem um processo estabelecido de priorização de demandas, necessidades de pequeno, médio e grande porte são tratadas de forma igual, o que faz com que a equipe acabe "apanhando" de todos. Ninguém fica feliz e sempre ficam com a impressão que estão atendendo um projeto que não necessariamente é o mais importante para a empresa e tampouco está alinhado com a estratégia da organização.

Por falar em estratégia, outra questão que incomoda muito Carlos é o fato de nunca ter sido convidado para participar das reuniões de planejamento estratégico da empresa, o que o deixa extremamente chateado e perdido. Ele somente recebe as demandas da diretoria após a reunião, fazendo com que ele chegue ao ponto de esbravejar: "Como posso ser uma TI estratégica se não participo do planejamento estratégico da empresa? Parece que os diretores não percebem que não existe se quer um projeto de novos negócios, novas ofertas ou melhoria de produtividade e que a TI não esteja envolvida de alguma forma. Praticamente participamos de todos os projetos da empresa, e parece que ninguém percebe isso, só sabem reclamar que o orçamento da TI está muito alto".

Carlos está ciente que tem muita coisa para melhorar no seu trabalho, na sua equipe, e também na empresa como um todo. Ele sabe que não dá para fazer tudo ao mesmo tempo e que, para mudar a cultura 
da equipe e da empresa, não será da noite para dia. Mas sabe também que precisa deixar de ser somente reativo, virar o jogo na empresa e também preparar o desenvolvimento da sua carreira profissional. Ele não pode ser somente mais um na equipe; ele é o gerente da área de TI. Antes que seja tarde demais para recuperar o prestigio e a moral da equipe, precisa apresentar para a diretoria uma solução para a área de $\mathrm{TI}$, demonstrando de forma clara e objetiva o cenário atual e o retorno que a empresa pode ter.

\section{Santo de casa não faz milagres}

Carlos sempre achou que poderia resolver tudo sozinho com sua equipe. Sempre que falavam em consultoria, dizia que não precisava, que daria conta do recado, que sua equipe era autodidata. Enfim, apesar dos seus amigos, que também eram gestores de TI em outras organizações, dizerem que ele precisava de apoio externo, que santo de casa não fazia milagres, ele relutou muito até aceitar que realmente precisava de ajuda. Há dois meses tentou iniciar esse projeto de melhoria internamente, mas não conseguia se dedicar e também faltava experiência em como estruturar esses novos processos, pois, nas outras empresas que tinha trabalhado, os processos já estavam estruturados. Demorou um tempo para reconhecer que a sua equipe não tinha a competência necessária para apresentar e executar um projeto dessa magnitude para conseguir virar o jogo e que não tinha mais chance para errar, pois já havia gasto todo o prestígio com desculpas em outros projetos.

Após algumas reflexões e conversas com sua equipe sobre o cenário atual da área de $\mathrm{TI}$, o grupo decidiu que iriam precisar de apoio externo de uma consultoria, e Carlos foi conversar com o seu diretor Celso. Explicou que precisaria contratar uma consultoria para ajudá-los a melhorar a performance da TI, que a equipe chegou a um consenso que dificilmente conseguiriam fazer sozinhos, e tinham decidido que, se fosse aprovado o projeto, todos assumiram o compromisso de melhorar o resultado. Carlos informou que a equipe conseguiria se dedicar 16 horas por semana para esse projeto, sem prejuízo às demais atividades.

Assim, Carlos seguiu em frente e pediu autorização para que ele buscasse uma empresa de consultoria especializada em processos de TI e gestão de projetos. Ressaltou que a consultoria não faz milagres, mas o grupo estava fechado para melhorar os resultados e a satisfação dos usuários. Celso escutou os argumentos, ponderou os pontos e, após alguns segundos de reflexão, autorizou que trouxessem uma empresa de consultoria para auxiliá-los. Já que era interesse de todos, inclusive dos acionistas, que a área de TI sofresse uma mudança rapidamente, autorizou a liberação de $\mathrm{R} \$ 80.000,00$ (oitenta mil reais) como limite de investimento para esse novo projeto que Carlos propôs. No entanto, reforçou que Carlos deveria ser assertivo na escolha da empresa e na estratégia do projeto.

Carlos foi à procura de uma consultoria que pudesse the ajudar, e ciente que não poderia errar, foi criterioso no processo de seleção. Buscou uma empresa de consultoria que estivesse consolidada no mercado, que não dependesse de um único consultor e que tivesse casos de sucesso na implementação de projetos similares à situação da sua área. Buscou referências com seus pares e amigos que atuam na área de $\mathrm{Tl}$ em outras empresas, e iniciou o contato com algumas consultorias que havia pré-selecionado.

Após algumas reuniões e entrevistas, Carlos escolheu a sua consultoria pela credibilidade que tinha no mercado, pelas boas referências de outros clientes, por ter metodologia própria baseada nas boas práticas do mercado e por apresentar a melhor relação custo x benefício. "Vamos implementar os processos necessários para melhorar a performance da área de TI, e assim, conseguir transformar a nossa atuação de reativa para estratégica.Vamos fazer uma reunião de lançamento para comunicar para toda empresa que vamos melhorar! Mãos à obra!", disse Carlos. Na sequência perguntou: Como vamos resolver toda essa insatisfação dos funcionários e colocar a área em ordem? 


\section{Anexos}

Anexo 1 - Lista de projetos da área de TI

\begin{tabular}{|c|c|c|c|c|}
\hline Seq. & Demanda & $\begin{array}{l}\text { Estimativa } \\
\text { de Esforço }\end{array}$ & Classificação & Situação \\
\hline 1 & Incluir campo nome do vendedor no relatório vendas & $16 \mathrm{hrs}$ & Melhoria & Atrasado \\
\hline 2 & Instalar 10 novos notebooks para gerentes & $40 \mathrm{hrs}$ & Melhoria & Atrasado \\
\hline 3 & Ajuste no relatório do sped fiscal & $40 \mathrm{hrs}$ & Legislação & Atrasado \\
\hline 4 & $\begin{array}{l}\text { Desenvolver ajuste no workflow de aprovação de } \\
\text { compras }\end{array}$ & $80 \mathrm{hrs}$ & Melhoria & Atrasado \\
\hline 5 & Novo relatório de análise de fornecedores & $120 \mathrm{hrs}$ & Melhoria & Atrasado \\
\hline 6 & $\begin{array}{l}\text { Baixar novo pacote de atualização do ERP para } \\
\text { resolver problema de logística }\end{array}$ & $100 \mathrm{hrs}$ & Melhoria & Atrasado \\
\hline 7 & Liberar acesso aos novos funcionários no ERP & 40 & Melhoria & Atrasado \\
\hline 8 & $\begin{array}{l}\text { Desenvolver novo sistema para gestão de despesas de } \\
\text { viagem }\end{array}$ & $800 \mathrm{hrs}$ & Melhoria & Atrasado \\
\hline 9 & Implantar novo sistema de força de vendas & $1.200 \mathrm{hrs}$ & Novos negócios & Atrasado \\
\hline 10 & Implantação do sistema na nova filial em SP & $600 \mathrm{hrs}$ & Novos negócios & Atrasado \\
\hline 11 & Implantação novo sistema de ponto eletrônico & $1.500 \mathrm{hrs}$ & Legislação & Atrasado \\
\hline 12 & Implantação sistema WMS & $2.500 \mathrm{hrs}$ & Melhoria & Andamento \\
\hline 13 & Otimizar processo de entregas & $1.800 \mathrm{hrs}$ & Melhoria & Andamento \\
\hline 14 & Redução de custos de embalagens & $700 \mathrm{hrs}$ & Melhoria & Andamento \\
\hline 15 & Novas funcionalidades no Força de Vendas & $650 \mathrm{hrs}$ & Melhoria & Andamento \\
\hline 16 & Implantar e-social para o RH & $960 \mathrm{hrs}$ & Legislação & Andamento \\
\hline 17 & Nova campanha de marketing & $550 \mathrm{hrs}$ & Novos negócios & Andamento \\
\hline 18 & $\begin{array}{c}\text { Implantar sistema de Planejamento avançado da } \\
\text { produção (APS) }\end{array}$ & $2.000 \mathrm{hrs}$ & Estratégico & Pendente \\
\hline 19 & Movimentação para novo Datacenter & $3.500 \mathrm{hrs}$ & Estratégico & Pendente \\
\hline 20 & Migração para nova versão do ERP & $15.000 \mathrm{hrs}$ & Estratégico & Pendente \\
\hline 21 & Implantar Escritório de Projetos na TI & $500 \mathrm{hrs}$ & Estratégico & Pendente \\
\hline
\end{tabular}




\section{NOTAS DE ENSINO}

\section{Objetivos de ensino}

Proporcionar a imersão dos leitores em uma situação de pressão por melhores resultados para a empresa, devido à má gestão dos projetos e processos em uma área de TI, e seu alinhamento com a estratégia da empresa, possibilitando a aprendizagem sobre esses temas.

\section{Fontes e métodos de coleta}

As informações utilizadas para a elaboração desse caso de ensino são baseadas em casos reais, em que foram utilizados dados adquiridos através de entrevistas semiestruturadas com gestores de TI de empresas e membros da equipe. Os nomes das personagens e das empresas citadas são fictícios.

\section{Relações com os objetivos de um curso ou disciplina}

O caso de ensino da TI reativa para uma TI estratégica foi desenvolvido para proporcionar a discussão sobre a importância das estratégias da área de TI estarem alinhadas com as estratégias da empresa, e o retorno que pode proporcionar para as organizações. O objetivo é fazer o aluno perceber a importância do alinhamento entre negócios e TI para que todos trilhem o mesmo caminho, com foco na missão, visão e objetivos da empresa, além de debater sobre boas práticas em gestão de processos, projetos e portfólio de projetos, e sobre as características de um profissional da gestão de projetos e TI.

E, por fim, trazer a discussão sobre os ingredientes necessários ao sucesso de um negócio: identificação e avaliação dos problemas na hora certa; planejamento cuidadoso e tomada de decisão; e como conduzir a mudança na cultura de uma organização que cresceu e se desenvolveu considerando a área de TI como um mal necessário, e não como um parceiro estratégico do negócio.

\section{Disciplinas sugeridas para uso do caso}

Este caso é recomendado para ser usado nas disciplinas de gestão de projetos e gestão de $\mathrm{TI}$ em cursos de gestão de projetos, de gestão de processos, de governança de TI, formação de executivos, MBAs, na graduação ou em cursos stricto sensu em administração, e demais cursos que envolvam as áreas de $\mathrm{TI}$ de empresas de todos os segmentos e tamanhos.

\section{Possíveis tarefas a propor aos alunos}

As questões do caso foram elaboradas com o propósito de proporcionar ao aluno o desenvolvimento de um aprendizado técnico, bem direcionado, com o auxílio de literaturas específicas e da consequente análise/discussão em sala.

1. Quais são suas recomendações para Carlos transformar a área de TI de reativa em uma TI estratégica?

2. Atender quem reclama mais é a melhor solução para esse contexto? Quais outras abordagens seriam mais efetivas para resolver o dilema de Carlos?

3. Que metodologia de gestão de projetos recomendaria para tratar as demandas de pequeno esforço? E qual para tratar os projetos de médio e grande porte? Justifique.

4. Como a área de TI pode demonstrar o retorno do investimento para a empresa?

5. Que processos podem ser implantados para melhorar a governança da área de $\mathrm{Tl}$ ?

\section{Possível organização da aula para uso do caso}

Sugere-se ao professor que: solicite a leitura prévia do caso e inicie o estudo de caso separando os alunos em grupos que irão representar a empresa de consultoria a ajudar Carlos com os dilemas. Cada 
equipe deverá escolher um nome para sua empresa. Na sequência, o professor deve solicitar que cada aluno faça um resgate das informações do caso individualmente. Em seguida, deve debater no grupo o que sua empresa de consultoria recomendaria para a situação em questão. Cada equipe deverá fazer um brainstorming para responder às questões trazidas no final do caso e, após todos terem terminado de respondê-las, orienta-se apresentar para os demais grupos e debaterem. Ao final, o professor deverá fazer um fechamento, podendo indicar a melhor alternativa caso nenhum grupo apresente uma sugestão adequada.

Como recurso de animação do debate, o professor pode pedir que os alunos se agrupem espacialmente na sala de acordo com suas opiniões iniciais, formando de três a cinco grupos. Pode ainda instigar o debate, dando a palavra alternadamente a cada grupo e registrar na lousa os argumentos, enfatizando os aspectos de cada proposta e da situação em que se encontra a empresa e a área de TI atualmente.

Qualquer que seja a estratégia que o professor adote para conduzir a discussão, deve ficar claro para os alunos, ao final, a importância da gestão de projetos, processos e de estratégias para demonstrar o valor da área de TI para uma organização.

O tempo total estimado é de 240 minutos para a execução dessa dinâmica (Quadro 1), podendo chegar a 300 minutos dependendo das discussões entre os grupos e o professor. Uma alternativa para conseguir agilizar o trabalho e conseguir concluir no período de três a quatro horas deaula é entregar o caso antecipadamente, para os alunos analisarem fora da aula e trazerem suas recomendações na aula seguinte para discutir em grupo e fechar o trabalho.

\section{Quadro 1 - Plano de Aula}

\begin{tabular}{|l|l|l|l|}
\hline Seq. & Pauta & Tempo estimado & Observação \\
\hline 1 & Abertura pelo Professor & 5 minutos & $\begin{array}{l}\text { Explicar o objetivo do exercício, e orientar a } \\
\text { distribuição dos grupos. }\end{array}$ \\
\hline 2 & $\begin{array}{l}\text { Resgate das informações } \\
\text { do caso de ensino }\end{array}$ & 15 minutos & $\begin{array}{l}\text { Cada aluno deverá reler as informações principais } \\
\text { do caso individualmente. }\end{array}$ \\
\hline 3 & $\begin{array}{l}\text { Responder as questões } \\
\text { O grupo deve debater as questões e anotar as } \\
\text { respostas numa folha com o nome do grupo. } \\
\text { Podendo registrar no ppt também para apresentar } \\
\text { no projetor as respostas. O professor poderá } \\
\text { entregar um modelo de Termo de Abertura para os } \\
\text { alunos responderem a primeira questão. }\end{array}$ \\
\hline 5 & $\begin{array}{l}\text { Apresentação do caso } \\
\text { aprendidas. }\end{array}$ & $\begin{array}{l}\text { Cada grupo terá 15 minutos para apresentar as } \\
\text { respostas e justificar. Dependendo o número de } \\
\text { grupos o tempo total irá variar. }\end{array}$ \\
\hline
\end{tabular}

\section{Análise do caso com suporte de literatura}

\section{Da TI de reativa para uma TI estratégica}

Nesta questão, é importante debater o quão necessária se faz a TI para a empresa e a necessidade do alinhamento aos negócios. Pesquisas recentes revelaram que o alinhamento da TI com a estratégia organizacional trouxe efeitos positivos no desempenho dos negócios (CHAN; SABHERWAL, 2001; OH; PINSONNEAULT, 2007; HU; YAYLA, 2012; GEROW; GROVER; THATCHER, 2014). O argumento central subjacente a esses estudos é que as organizações têm um bom desempenho quando os principais recursos da TI, como componentes físicos, infraestrutura, habilidades, técnicas de gestão e ativos de conhecimento estão alinhados com a estratégia de negócios, e quando as estruturas adequadas são usadas para supervisionar a implementação e gestão eficaz desses recursos (KARAHANNA; PRESTON, 2009).

Um grande desafio para todos os gestores de TI é tornar sua área um parceiro estratégico da organização. Preston (2014) identifica o alinhamento de TI como a terceira mais importante "prioridade", 
ou "área de preocupação", para os CEOs. Isso demonstra a necessidade de debate e desenvolvimento sobre o tema.

Embora o estudo do alinhamento estratégico de TI tenha tido progressos significativos no último quarto de século, desde o trabalho de Henderson, Venkatraman e outros, ainda há várias questões importantes de pesquisa que são relativamente inexploradas. O fato de que o alinhamento de $\mathrm{Tl}$ é uma prioridade permanente dos CEOs confirma que o alinhamento é difícil, mas também mostra que é um alvo em movimento. Com isso, pode ser mais importante do que nunca manter o alinhamento da TI com o negócio, ao passo que, do contrário poderia levar a um declínio no desempenho da empresa e uma erosão no estado de competitividade no mercado e agilidade nos negócios (COLTMAN et al., 2015).

Ao olhar para o futuro, observam-se três temas-chave que irão orientar futuras pesquisas sobre o alinhamento de TI. Esses temas são: (1) as micro fundações do alinhamento de TI, (2) o aumento da estratégia de negócio digital, e (3) co-criação do ecossistema de inovação e valor. Esses três temas formam um ponto de partida para o desenvolvimento de um amplo conjunto de questões para orientar o alinhamento da TI e para dirigir os gestores e executivos para os desafios e oportunidades que se avizinham para o alinhamento de TI (COLTMAN et al., 2015).

Como foi observado por Carlos, parece que os diretores não percebem que não existe sequer um projeto de novos negócios, novas ofertas ou de melhoria de produtividade em que a TI não esteja envolvida de alguma forma. A TI participa de praticamente todos os projetos da empresa, mas, com frequência, os gestores não percebem isso, é o que apontam as pesquisas (COLTMAN et al., 2015). Atualmente, é isto que se percebe nas organizações.

Toledo et al. (2008) elenca algumas ações que devem ser colocadas em prática nas áreas de TI que poderiam ser utilizadas por Carlos para alcançar um alinhamento estratégico da TI com a organização:

- Desenvolver um processo de inovação na área de TI para que a empresa esteja sempre atualizada em relação às novas tecnologias e possa propor novas alternativas para o negócio, assim como dar retorno às sugestões apresentadas por toda a equipe;

- Levantar o retorno do investimento de cada demanda de novos projetos e demonstrar para os acionistas onde foi investido o orçamento de $\mathrm{TI}$ e o retorno que trouxe para a empresa, comprovando através de auditorias após a implantação dos projetos;

- Solicitar que possa participar das reuniões do planejamento estratégico da empresa;

- Desenvolver as competências da equipe de TI em boas práticas da área de Tl e também em boas práticas de negócios;

- Implantar um escritório de projetos e processos para melhorar a governança da área e mitigar riscos;

- Atuar de modo proativo.

Com algumas dessas ações, Carlos conseguirá mudar a sua imagem e da sua equipe de TI frente aos outros integrantes da empresa, visto que poderá apresentar um produto final mais rapidamente para seus gestores e comprovar o retorno do valor investido na área através de auditorias nos projetos entregues. Também conquistará o respeito e poderá demonstrar sua importância ao participar das reuniões. Desenvolvendo as competências da equipe, poderá se posicionar de forma mais estratégica; e com a implantação do escritório de projetos e uma ação mais proativa, conseguirá facilmente demonstrar aos seus gestores que a área da TI deixou de ser reativaestando alinhada à estratégia da organização.

\section{Métodos de Priorização de Projetos}

Conforme especificado no caso, atualmente, quem reclama mais é atendido primeiro. Esta não é a melhor solução a ser aplicada. Tendo em vista que Carlos está sendo bastante pressionado por todas as áreas pelos projetos atrasados, não consegue atender a todos como gostaria, pois são muitos projetos e atividades para fazer e gerenciar ao mesmo tempo; também não consegue ter um acompanhamento da posição de todas as demandas e não sabe se a produtividade da equipe está adequada. Nesse caso, o 
processo adequado a ser implantado é o processo de gestão de portfólio de projetos de TI. Esse processo tem por objetivo selecionar, categorizar e definir critérios para autorização dos projetos alinhados com a estratégia da organização.

De acordo com Junqueira (2011), os elementos da gestão de portfólio de TI existem em todas as organizações, trabalhando vários projetos em um único portfólio, com objetivos comuns de resultado, e possuem praticamente as mesmas metas e objetivos: maximizar o valor, tanto tangível como intangível, e administrar riscos e custos. Com a intenção de direcionar corretamente esses elementos para os objetivos, faz-se essencial obter-se informações sobre cada projeto e os investimentos necessários, destacando os aspectos positivos e negativos de cada investimento. A análise do portfólio de TI fornece informações como: as áreas específicas que necessitam de melhorias; as falhas nos requisitos e arquitetura; se existe desalinhamento com a estratégia corporativa; as áreas bem atendidas e as que necessitam de atenção e assim por diante. Portanto, delimita e alinha todas as informações necessárias para Carlos poder tomar as decisões que precisa, como quais projetos deve desenvolver primeiro.

Bonham (2005) propõem que a Gestão de Portfólio de Projetos de Tecnologia da Informação (GPPTIC) seja executada através dos seguintes passos:

- Estabelecer um time de gestão de portfólio que seja multifuncional e garanta uma visão e decisão que contemple as várias necessidade e diversidades;

- Realizar um inventário dos projetos de TIC com as informações que darão suporte ao processo de tomada de decisão;

- Realizar o alinhamento dos projetos de TIC em relação às metas identificadas;

- Priorizar os projetos com base em algum critério objetivo (sistemas de escoragem);

- Alocar recursos aos projetos com maior pontuação no sistema de escoragem;

- Reavaliar regularmente o portfólio de projeto de TIC para garantir constante alinhamento dos projetos de TIC às metas da organização;

- Avaliar os benefícios propostos pelos projetos de TIC.

- Entender as metas estratégicas da organização para entender como os projetos de TIC devem responder às metas;

Existem ainda, de acordo com Carvalho (2006), alguns métodos que podem ser utilizados para a priorização de projetos, como: o método Gravidade x Urgência x Tendência (GUT). O método GUT é uma ferramenta que dá suporte na priorização de resoluções. A matriz serve para classificar cada projeto que se julga pertinente para a empresa pela ótica da gravidade do projeto, que é analisada pela consideração da intensidade ou impacto que o projeto pode causar se não for solucionado; da urgência, que é analisada pela pressão do tempo que existe para resolver determinada situação; e pela tendência de o projeto piorar com rapidez ou de forma lenta. É analisada pelo padrão ou tendência de evolução da situação.

Pode-se utilizar ainda o método Analytic Hierarchy Process (AHP), que serve para auxiliar na tomada de decisões complexas. O AHP representa e quantifica as variáveis envolvidas em uma escala hierárquica de critérios pré-definidos por preferências, que possuem pesos. O resultado é um modelo que permite analisar várias alternativas e as comparar rapidamente. O AHP, portanto, é um modelo que transforma as preferências, ou julgamentos humanos, em valores numéricos para construir um modelo de tomada de decisão.

Nessa questão, o instrutor tem a alternativa de solicitar para que cada grupo explore um dos métodos citados ou outros métodos, podendo até trazer uma sugestão de critérios escolhida pelo próprio grupo. Pode-se utilizar o Anexo 1 para elaborar uma matriz de priorização com base nos métodos a serem apresentados.

\section{Metodologias de Gestão de Projetos}

Para Carvalho e Mello (2009), para o tratamento de projetos com estimativa de baixo esforço e/ou que não tenham um escopo bem definido no início do projeto, recomenda-se utilizar uma metodologia ágil 
de gestão de projetos baseada no método Scrum. Esse método segue os princípios do Manifesto Ágil, preconizado por três de seus signatários: Mike Beedle, Ken Schwaber e Jeff Sutherland. Os valores do Manifesto ágil trazem sugestões para a melhoria de métodos, processos e técnicas de desenvolvimento e gestão de projetos.

Os benefícios do Scrum mais citados na literatura são os seguintes (em ordem de número de citações): melhoria na comunicação e aumento da colaboração entre envolvidos; melhoria da qualidade do produto produzido; aumento de produtividade da equipe; aumento da satisfação de clientes (diminuição de reclamações); aumento do retorno do investimento do projeto; aumento da motivação da equipe de desenvolvimento; diminuição dos custos de produção (mão de obra); diminuição no tempo gasto para terminar o projeto (prazo); diminuição do risco do projeto (menor possibilidade de insucesso) (CARVALHO; MELLO, 2009).

A metodologia SCRUM é considerada muito ágil e flexível, e tem por objetivo definir um processo de desenvolvimento interativo e incremental, que pode ser aplicado no gerenciamento de qualquer atividade ou produto, proporcionando um excelente entrosamento entre as equipes de desenvolvimento e comunicação mais efetiva.

Para o desenvolvimento de projetos mais complexos, com escopo e orçamento bem definidos, envolvendo equipes internas e externas, com prazos determinados e acordados com os clientes, recomenda-se a utilização de uma metodologia tradicional, baseada nas boas práticas preconizadas no Guia PMBOK®, $5^{\text {a }}$ edição do PMI.

\section{Retorno do investimento e governança de TI}

A governança de $\mathrm{TI}$, propriamente dita, envolve a aplicação de princípios de governança corporativa para dirigir e controlar a TI de forma estratégica, preocupando-se exclusivamente com dois assuntoschave: o valor que a TI proporciona à organização, e o controle e a diminuição dos riscos relacionados à TI (LUNARDI; BECKER; MAÇADA, 2010 apud ITGI, 2003). O primeiro assunto é direcionado pelo alinhamento estratégico entre os negócios e a tecnologia, enquanto o segundo é direcionado pela definição dos responsáveis na organização pelas decisões envolvendo os assuntos ligados à TI. Ambos precisam ser suportados por medidas e recursos adequados para que os resultados desejados sejam alcançados (ITGI, 2003).

Para Fernandes e Abreu (2014), o principal objetivo da ggovernança de TI é alinhar a TI aos requisitos do negócio, considerando soluções de apoio ao negócio, assim como a garantia da continuidade dos serviços e a minimização da exposição do negócio aos riscos de TI.

Quando os processos de governança são bem planejados, cada aspecto da organização é coordenado. As pessoas, os equipamentos e os recursos financeiros trabalham em conjunto, em direção aos objetivos estratégicos da organização. Nesse sentido, estruturar e definir quais mecanismos de governança de TI devem ser implementados torna-se relevante para que as organizações possam gerenciar melhor os seus ativos de $\mathrm{TI}$ e, por conseguinte, obter maior retorno a partir dos investimentos que vêm realizando (BECKER; LUNARDI; MAÇADA, 2010).

Uma pesquisa realizada com 83 executivos de TI, em 81 empresas, pelos autores Becker, Lunardi e Maçada (2010), demonstrou que o Planejamento Estratégico da TI (PETI), a análise de viabilidade de projetos de $\mathrm{Tl}$ e o uso de comitês para projetos específicos de $\mathrm{Tl}$ aparecem como os mecanismos mais utilizados pelas empresas analisadas para a governança da TI. Segundo os autores da pesquisa, os mecanismos que mais afetam o desempenho (percebido) da gestão da TI são o PETI, o comitê de projetos específicos de TI, a participação do ClO (Chief Information Officer - diretor de TI) na formulação da estratégia da empresa, as práticas de compliance e os comitês de TI. Os resultados da investigação sugerem que, quanto mais efetivos forem os mecanismos de governança de TI, melhor será o desempenho da gestão de TI na organização.

O resultado da pesquisa apresentou também que os mecanismos mais fortemente associados com as áreas foco da governança de TI são: (1) o comitê de projetos de TI; (2) as práticas formais de 
comunicação; (3) a participação do CIO na formulação da estratégia da organização; (4) os acordos de nível de serviço (SLA/SLM); (5) a presença de comitês de TI; (6) o uso do escritório de projetos; e (7) o uso do balanced scorecard.

\section{Referências}

BONHAM, S. S. IT project portfolio management. New York: Artech House, 2004. 264 p.

BRITTO, R. Gerenciamento de projeto: criando o termo de abertura III. Project Management Knowledge Base, 2013. Disponível em: <http://pmkb.com.br/artigo/gerenciamento-de-projeto-criando-otermo-de-abertura-iii>. Acesso em: 25 abr. 2016.

CARVALHO, B. V.; MELLO, C. H. P. Revisão, análise e classificação da literatura sobre o método de desenvolvimento de produtos ágil Scrum. In: SIMPÓSIO DE ADMINISTRAÇÃO DA PRODUÇÃO, LOGÍSTICA E OPERAÇÕES INTERNACIONAIS, 12., 2009, São Paulo. Anais... São Paulo:SIMPOI, 2009.

CARVALHO, M. M.; RABECHINI JR., R. Gerenciamento de projetos na prática:casos brasileiros.São Paulo: Atlas, 2006. v. 1.

COLTMAN, T. et al. Strategic IT alignment: twenty-five years on. Journal of Information Technology, [S.I], v. 30, n. 2, p. 91-100, Jun. 2015.

DISNMORE, P. C.; SILVEIRA NETO, F. H. Gerenciamento de projetos: como gerenciar seu projeto com qualidade, dentro do prazo e custos previstos. 2 ed. Rio de janeiro: Qualitymark, 2013.

FERNANDES, A. A.; ABREU, V. F. Implantando a governança de TI: da estratégia à gestão de processos e serviços. 4 ed. Rio de Janeiro: Brasport, 2014. 656 p.

GEROW, J. E.; THATCHER, J. B.; GROVER, V. Six types of IT-business strategic alignment: an investigation of the constructs and their measurement. European Journal of Information Systems, [S,I], v. 24, n. 5, p. 465-491, Sept. 2015.

JUNQUEIRA, J. C. Metodologias de gestão de portfólio de projetos de TI. In: ENCONTRO ANUAL DA ASSOCIAÇÃO NACIONAL DOS PROGRAMAS DE PÓS-GRADUAÇÃO EM ADMINISTRAÇÃO, 35., 2011, Rio de Janeiro. Anais... Rio de Janeiro: ANPAD, p. 1 - 17, 2011.

LUNARDI, G. L.; BECKER, J. L.; MAÇADA, A. C. G. Impacto da adoção de mecanismos de governança de tecnologia de informação ( $\mathrm{TI})$ no desempenho da gestão da TI: uma análise baseada na percepção dos executivos. Revista de Ciências da Administração, Florianópolis /SC, v. 12, n. 28, p. 11-39, set./ dez. 2010.

$\mathrm{OH}, \mathrm{W}$.; PINSONNEAULT, A. On the assessment of the strategic value of information technologies: conceptual and analytical approaches. MIS Quarterly, [S.I], v. 31, n. 2, p. 239-265, Jun. 2007.

PRESTON, D. S.; KARAHANNA, E. Antecedents of IS strategic alignment: a nomological network. Information Systems Research, [S.I], v. 20, n. 2, p. 159-179, 2009.

PRESTON, R. CIO worries: security, talent and (sadly) 'alignment'. Information Week. 2014. Disponível em: <http://www.informationweek.com/strategic-cio/digital-business/cio-worries-security-talent-and(sadly)-alignment/a/d-id/1315575>. Acesso em: 25 abr. 2016.

PROJECT MANAGEMENT INSTITUTE. A Guide to the Project Management Body of Knowledge. 5 ed. Pennsylvania: Project Management Institute, 2013. 589 p.

SABHERWAL, R.; CHAN, Y. E. Alignment between business and IS strategies: a study of prospectors, analyzers, and defenders. Information Systems Research, Catonsville, v. 12, n. 1, p. 11-33, 2001.

SILVA, F.Como elaborar um termo de abertura de projeto. Project Management Knowledge Base Conhecimento e Experiência em Gerenciamento de Projetos, 2011. Disponível em: <http://pmkb.com.br/ 
artigo/como-elaborar-um-termo-de-abertura-do-projeto>. Acesso em: 25 abr. 2016.

TOLEDO, J. C. et al. Fatores críticos de sucesso no gerenciamento de projetos de desenvolvimento de produto em empresas de base tecnológica de pequeno e médio porte. Gestão e Produção, São Carlos, v. 15, n. 1, p. 117-134, 2008. Disponível em: <http://www.scielo.br/scielo.php?script=sci_ arttext\&pid=S0104-530X2008000100011>. Acesso em: 01 abr. 2016.

WESTLAND, J. R. et al. How to make your project chart. Wikihow, 2013. Disponível em: <http://www. wikihow.com/Make-Your-Project-Charter>.Acesso em: 25 abr. 2016.

YAYLA, A. A.; HU, Q. The impact of IT-business strategic alignment on firm performance in a developing country setting: exploring moderating roles of environmental uncertainty and strategic orientation.

European Journal of Information Systems,[S.I], v. 21, n. 4, p. 373-387, 2012.

Submetido em: 16/12/2016

Aprovado em: 17/09/2017 